\title{
El problema judío en la mente de tres importantes personajes del siglo vil: un papa, un obispo español y un rey visigodo *
}

\author{
A. Riesco Terrero **
}

\section{MARCO HISTÓRICO}

El «antisemitismo» y más concretamente el "antijudaísmo», aparte de fenómeno complejo, es tan antiguo y nuevo como el propio pueblo de Israel. Pero tal vez sea más importante caer en la cuenta de que esa animadversión, a veces, odio, indiferencia, antipatía, persecución... ha actuado como eficaz revulsivo, convirtiéndose para muchos en afecto, simpatía y admiración o, por lo menos, en una de las causas principales y de mayor interés por la historia del pueblo judío.

Como quiera que sea, el tema de los judíos está tan vinculado a nuestra civilización y cultura occidental, a nuestra economía, historia y religión cristiana que difícilmente puede prescindirse del importante papel desarrollado por ellos dentro de los distintos núcleos urbanos, colonias y sociedades en que este pueblo disperso ha vivido inmerso y, en particular, dentro de la sociedad española, de la que hace cinco siglos por imperativo de la ley tuvo que desvincularse.

Existen, no obstante, otras razones de interés por conocer la vida e historia del pueblo hebreo y, también, por entender las principales raices y causas del antijudaísmo.

Se parte, en muchos casos, de posturas antagónicas remontables a épocas ancestrales, con frecuencia incongruentes y de escasa solidez, en

* Comunicación presentada en el Encuentro Internacional de Historiadores «En torno a Sefarad». Toledo 1991.

* Catedrático UCM. 
las que suelen involucrarse demasiados hechos y cosas que, nada o muy poco, tienen que ver con el pueblo judío y su problemática.

A mi entender, en este asunto - como en otros muchos- hay mucha exageración e inexactitud, y no falta el error y, sobre todo, lo tendencioso y subjetivo. La simpatía o antipatía, el activismo sociopolítico, la presión religiosa y política imperantes, de uno u otro signo, etc., representan una serie de concausas explicativas o mejor aclaratorias de determinadas posturas y fenómenos, pero no creo que deban atribuirse exclusivamente -al menos en lo que respecta al antijudaísmo- a las autoridades civiles y religiosas, $o$ al influjo de obras y escritos de especialistas procedentes de distintos campos y ambientes culturales e ideológicos. La intolerancia y cerrazón de ciertos judíos, empeñados en mantener para sus conciudadanos la visión y perspectiva peculiar del "gueto" no ha favorecido la causa judía, más bien ha contribuido a mantener la incomprensión y el estigma negativo, aún no superados por muchos.

Considero demasiado simplista la opinión de quienes creen que el trato benevolente $\mathrm{y}$-en términos generales - hasta privilegiado, otorgado por los emperadores romanos al pueblo judío y a las distintas colonias dispersas por el Imperio hasta la diáspora, salvo en ocasiones contadas, como fueron, por ejemplo, el ataque al templo de Jerusalén o la catástrofe del año 70 de nuestra era, en tiempos de Vespasiano, y la actitud abiertamente persecutoria de Adriano a raíz de la segunda guerra judía (aa. 132-135 d.C.) se deben exclusivamente a motivos sociopolíticos y económicos.

Tampoco es verdad que el odio, la discriminación y las medidas represivas antijudías procedan sólo de concepciones religiosas de signo contrario, atribuibles en exclusiva al cristianismo y, más concretamente, a España y a los españoles.

Las medidas, a que acabo de aludir, recogidas en diversidad de cuerpos legislativos españoles y de fuera de nuestras fronteras y, en especial, los cánones eclesiásticos de los siglos III-VII (Sínodos provinciales hispanoromanos y Concilios de Toledo) y las leyes y decretos insertos en códigos tan representativos para España como el Código y las Novelas de Justiniano, el Fuero Juzgo... y los calificativos con que se identifica a los judíos: «usureros, fanáticos, infieles, perjuros, herejes, incrédulos, marranos, blasfemos, desertores, rebeldes, apostatas, traidores, enemigos de la fe y de la cruz de Cristo...", nos obligan a pensar en un cúmulo de razones y circunstarcias de difícil comprensión para nuestra mentalidad actual pero de indudable valor e importancia para los criterios de entonces que, a mi modo de ver, superan el campo de lo político, de lo económico y aún de lo religioso. 
Lo cierto es que desde el mandato de Graciano (siglo Iv ) los judíos vieron mermados, cuando no suprimidos, sus privilegios y libertades y que, a partir de Constantino I, su boyante situación social y política experimenta los primeros síntomas de decadencia y desprestigio; situación que irá acentuándose -al menos por lo que a España y parte de las Galias (Narbonense) se refiere- durante la dominación visigoda de Alarico II (aa. 484-507) a Egica, a finales del siglo VII.

Es indudable que la acendrada religiosidad y su conciencia de raza y pueblo singular: teocrático, elegido y único, favoreció la vida, comportamiento, costumbres y peculiaridades de la gente judía aún antes de la dispersión, pero mucho más después de ella. Hay, no obstante, otras circunstancias de capital importancia v.gr. la preponderancia judía en campos tan importantes como el socio-económico, el administrativo, el judicial, el mercantil y financiero, el laboral, etc., que actúan como elemento aglutinante e impermeabilizador entre los miembros de las distintas colonias hebreas y que, dentro del gueto, sirvieron para fomentar una especie de integrismo comunitario impenetrable, de signo político-religioso e ideológico que, a la larga, llevaría a todos sus miembros, o a buena parte de ellos, a adoptar formas de vida, actitudes y posturas incómodas para con quienes se relacionaron con ellos por razón del entorno geográfico, político, social y religioso en que convivieron.

Al monopolio y control, por parte de los judíos, de amplios e importantes sectores de distintas actividades sociales, económicas, laborales... hay que añadir su enfrentamiento y radical oposición al cristianismo y, sobre todo, su afán acaparador y proselitista que tanto dificultó su integración en los pueblos y nacionalidades de su entorno.

Este conjunto de circunstancias y realidades de todo tipo, enumeradas más arriba, y la propia condición socio-religiosa de los judios, puso en guardia y, a veces, en abierta lucha, no sólo a los poderes públicos y religiosos sino también al pueblo llano quien, con dificultad, pudo entender, y menos admitir, muchas de sus costumbres, actitudes y posturas.

Esta imagen general, un tanto negativa, es indudablemente parcial e inexacta y no explica el porqué del antijudaísmo ni refleja con nitidez la realidad del pueblo judío. De ahí que considera erróneo aplicarla a cada una de las comunidades hebreas y absurdo atribuirla a cada israelista pero, desgraciadamente, por falta de objetividad, por los muchos prejuicios existentes sobre el tema o por motivaciones de orden político, religioso, racista... sigue en pie, aunque indudablemente mucho más diluida $y \sin$ las estridencias de hace siglos.

Sería lamentable, aparte de injusto y falso, que los propios hispanos, manipulados por corrientes informativas tendenciosas y de presión o por 
la política partidista de turno $o$, acaso, por intereses y resentimientos ocultos, por desconocimiento de toda la verdad $y$, sobre todo, por considerar exclusivamente los posibles y reales defectos y puntos flacos -que los hubo- de acontecimientos de capital importancia para nuestra cultura e historia, como lo fueron el descubrimiento del Nuevo Mundo y el decreto de expulsión de los judíos, utilizásemos el año 1992 como plataforma para reavivar una nueva leyenda negra, denodando con calificativos denigrantes de "genocidas", "sanguinarios" y «crueles" no sólo a los protagonistas de tal gesta y disposición: Los Reyes Católicos, sino también y, principalmente a España y al actual pueblo español que, en estos momentos, no guarda ningún resentimiento contra las naciones y ciudadanos hispanoamericanos y menos contra el pueblo y raza judía.

\section{NORMATIVA CANÓNICO-CIVIL DE LOS SIGLOS IV-VII SOBRE ASUNTOS RELACIONADOS CON LOS JUDIOS, EL CULTO Y LAS FIESTAS, EL AYUNO Y LA ADMINISTRACIÓN DE LOS SACRAMENTOS ${ }^{1}$}

Prescindiendo de la producción patrística de los primeros siglos del cristianismo (siglos I-III), seguramente los cánones del Concilio de Elvira, de principios del siglo iv y la normativa de los Canones Apostolorum, colección reunida hacia el año 400 , constituyen una de las principales fuentes legislativas de origen eclesiástico en que se aborda, con carácter más regional que general, el viejo y polémico problema de las relaciones entre judíos y cristianos, máxime en puntos relativos a la incorporación y paso de miembros de una comunidad y religión a otra, en la celebración del culto y festividades, en la observancia de los preceptos, ritos y creencias y en el trato cotidiano de personas que forzosamente tenían que convivir.

La diversidad de costumbres, preceptos, ritos, ceremonias y creencias, en unos casos, dio lugar a la separación total y anatagónica y, en otros, bien a la persecución y confrontación virulenta, bien a la tolerancia mitigada.

García IGLesias, L., en su obra Los judíos en la España antigua. Madrid 1978 y KING, P. D., en Derecho y sociedad en el reino visigodo. Madrid 1981, ofrecen abundante bibliografía sobre esta temática. Para la normativa conciliar, he utilizado como fuentes principales, las co. lecciones siguientes.J. D. Mansi, Loaisa y Aguirre, los "Concilios visigóticos e Hispano-romanos" de J. Vives, T. Marin y G. Martinez, y el "Enchiridion Fontium Historiae Antiquae" de C. $\mathrm{KIRCH}$. Y con relación a la legislación civil el "Corpus luris Civilis", ed. de Mommsen, Krieger y Schöll y las "Leges Visigothorum" del MGH para el estudio de la documentación pontificia relativa a los judíos considero de gran utilidad e interés la obra publicada en Toronto por el Instituto Pontificio de Estudios Medievales, editada en 3 volúmenes por S. SIMONSOHN, bajo el título: The Apostolic see and the Jews. Documents. Toronto 1988-1990. Para nuestro estudio, el vol. I, que abarca del año 492 al 1404 , es el más útil. 
Las vejaciones y penalidades impuestas a los cristianos por parte de herejes, arrianos y paganos durante el mandato de emperadores intransigentes con la nueva Iglesia - de Nerón (siglo I) a Juliano el Apóstata (siglo IV), pasando por Domiciano, Trajano, Marco Aurelio, Séptimo Severo, Decio Valeriano, Maximiano y Diocleciano... o simplemente tolerantes y benévolos como Caracalla, Severo Alejandro, Felipe el Árabe, Joviano, Graciano y Valentiniano I y II-, provocaron la persecución imperial, el enfrentamiento y la hostilidad entre cristianos y judíos y entre cristianos y paganos $o$ arrianos y, en períodos de paz y protección civil y religiosa o de excesiva cofraternización, entre pueblos de distinta entidad y religión, el enfrentamiento espiritual, la indiferencia religiosa y la relajación de costumbres. Así lo insinúan - con relación al último punto- las actas de los concilios hispanos-romanos del siglo IV.

En toda esta complicada problemática, con diversidad de matices y situaciones, hay mucho de fanatismo, de suspicacia, recelo y temor, sin que falten razones ideológicas y de Estado (político-sociales) y posturas pendulares: favorables $u$ hostiles, de la autoridad imperial, de las propias instituciones y de la sociedad.

Los llamados Cánones de los Apóstoles (c. 7) y con anterioridad el Concilio de Arles I (a.314, c. 1) y el Niceno I (a. 32 5, c. 3) prohíben a obispos, presbíteros y diáconos de la Iglesia católica celebrar la festividad de la Pascua de Resurrección con los judíos, pero es en el concilio itiberitano donde se abordan problemas de suma importancia para aquella época y mentalidad v.gr. los matrimonios mixtos (c. 16) y el adulterio entre cristiano y judía o pagana (c. 78), uniones prohibidas desde muy antiguo por la ley y costumbres judías y durante los siglos iv y $\vee$ por los emperadores: Graciano, Teodosio I y II, Arcadio y Valentiniano II y III, por considerar que tales uniones y mezclas, aparte de ser ofensivas para las religiones monoteistas, suponían un peligro para la paz y convivencia entre pueblos y razas con ideologías, costumbres y normativas legales tan distintas.

Otra problemática no menos importante para aquella Iglesia local (IIliberis) y para sus representantes legítimos: los padres congregados en Elvira, fue la regulación de la convivencia y relaciones entre cristianos y gentiles o infieles, entendiendo por tales a los herejes, judíos y paganos.

El roce y trato familiar a que obligaba la participación de los cristianos en comidas, festejos y ágapes rituales, organizados por los judíos, implicaba el sometimiento de aquéllos a las costumbres y prescripciones alimentarias judías (c. 50) e inducía al pueblo sencillo a llamar y dar preferencia a jueces y ministros israelies, humillando asi a los sacerdotes y religión cristiana, máxime a la hora de percibir, por contrato o ajuste de 
cuentas, lo ofrecido a los ídolos e, igualmente, en el momento de bendecir las propiedades y frutos de las tierras pertenecientes a los cristianos (cc. 40 y 49 ).

A mi entender -en los cánones precedentes y en otros pertenecientes al mismo sínodo (cc. $26,36,42,61$ ) o a concilios y sínodos provinciales de España, de las Galias, etc., con normativa específica sobre matrimonios mixtos, impedimentos matrimoniales entre consanguíneos y afines, bailes y costumbres licenciosas, santificación y celebración de domingos y fiestas, ayuno sabático, prohibición para los cristianos de acudir a los tribunales judíos y de ser sus criados y esclavos o de someterse a la circuncisión y demás ritos judíos - no se trata, en la mayoría de los casos, de consideraciones puramente doctrinales ni de abierta confrontación cristiano-judía sino de normas prácticas encaminadas a erradicar peligros y problemas reales como lo eran: las rebeliones, la judaización, los "lapsi» y "relapsi», los herejes, los indiferentes, renegados o despreocupados... ante el problema religioso? ${ }^{2}$.

Si no se atajaban con remedios eficaces la osadía de los herejes, las costumbres licenciosas y paganas, las sediciones, el afán proselitista y las presiones de los judaizantes, ejercidas de forma personal o comunitaria sobre el incipiente $y$, a veces, indefenso cristianismo hispano, difícilmente podía avanzar la evangelización del pueblo y la expansión del cristianismo.

La convivencia y roce constante entre personas y grupos pertenecientes a religiones distintas con niveles culturales, sociales y económicos tan diferentes - unos, en posición privilegiada y de proteccionismo imperial y aristocrático, como ocurrió a numerosas colonias y comunidades judías afincadas en territorio hispano y, otros: los nuevos cristianos, en situación de inferioridad y escasa influencia - conducia, ciertamente, a la permisividad y relajación de costumbres pero también a cierto enfriamiento espiritual y a la contaminación ambiental en cuanto a religiosidad popular y práctica de los preceptos cristianos, tanto en épocas de paz y tolerancia como en períodos de laxitud y despreocupación por parte de la jerarquía católica.

2 Sobre estos puntos legislaron, entre otros, los siguientes concilios: Ancyra (año 314), Elvira (principios del siglo IV), Nicea (año 325), Laodicea (entre años 343-381), Zaragoza (año 380), Toledanos del I al VIII (entre años 379-653), I y II de Arlés (años 314 y 443), Tarragona (año 516), Agdé (año 506), Gerona (año 517), Orléans I y II (años 511 y 538), Barcelona (año 540), Lérida (año 546), Valencia (año 549), Braga I, II y III (años 561, 572 y 675), Narbona (año 589) y Sevilla (año 619). 
Sólo en tiempos de Recadero (aa. 586-601), tras su abjuración del arrianismo, con el apoyo moral del papa San Gegorio Magno (a. 599) y de los 72 obispos hispano-galos, reunidos en Toledo el año 589 (III Concilio de Toledo, c. 14) para condenar la herejía arriana en España, se adoptan medidas gubernamentales y eclesiásticas de sabor antijudío en cuanto al carácter punitivo de las transgresiones y una mayor intransigencia en temas relacionados con la doctrina y verdades cristianas $y$, sobre todo, en lo tocantes a vinculaciones matrimoniales mixtas, contratos de servidumbre y esclavitud o en cualquier otro tipo de relación que supusiera para los católicos sometimiento religioso, judicial o autoritario, por razón de simpatía, conveniencia, circuncisión forzada, cargo público...

Es en el siglo VII, tras la muerte de Witerico, cuando se urgen con violencia y dureza las leyes eclesiásticas contra lo judíos, iniciándose una política: civil y eclesiástica, intolerante y abiertamente antijudía, como lo ponen de manifiesto las disposiciones reales de Sisebuto, Suintila, Sisenado y Chintila (aa.612-639) y las actas de los Concilios Toledanos IV y VI de los años 633 y 638, en sus cánones 57-66 y 4, respectivamente ${ }^{3}$.

San Isidro de Sevilla, en distintos pasajes sobre la mesianidad de Cristo y la verdad de su mensaje (cristianismo), al enjuiciar el error de los judíos y gentiles, apegados al Antiguo Testamento (Ley antigua mosaica con su símbolo: la sinagoga) o a las costumbres paganas (arrianos), en lugar de anatematizar y polemizar contra los que rechazan la vocación divina a formar parte de la nueva institución: la Iglesia cristiana, prefiere el camino de la edificación instructiva y el convencimiento a las medidas de fuerza y represión. De ahí que trate de disculpar el rigor y postura antijudía de los monarcas visigodos que, por ignorancia, egoísmo, equivocación, rivalidad, convicción, falsos celos o por supuestas razones políticas, obligaron a gentiles y judíos a abrazar la fe católica y a bautizarse $^{4}$.

\section{EL PAPA HONORIO I (AÑOS 625-638) Y LOS JUDIOOS}

Gracias a la carta de contestación que el obispo de Zaragoza, San Braulio, dirige al papa Honorio l el año 638, en nombre de los obispos

3 Leges Visigothorum, ed. K. Zeumer, MGH, Secc. Leges I. Hannover-Leipzig 1902 y la de la R. Academia de la Historia: Legis Romanae Wisigothorum Fragmenta ex Codice Palimpsesto Sanctae Legionensis Ecclesiae. Madrid 1896.

“ ISIDORO, S., "Historia Gothorum" y "De fide catholica (ex vetere et novo testamento) contra ludaeos Libri duo", PL 83, 449 y ss., y Willians, A. L., Adversus ludaeos. Cambridge 1935 E. A. THOMPSON, en su obra "The goths in Spain". Oxford, traducida al español por J. Faci bajo el título: Los Godos en España. Madrid 1971, considera servil el elogio que S. Isidoro hizo del rey Suintila en su primera versión de la "Historia de los Godos", pág. 194 ed. esp. 
de España y de la Galia Narbonense totius Hispaniae atque Narbonensis Galliae, reunidos en la Iglesia de Santa Leocadia para celebrar el VI Concilio de Toledo, conocemos - aunque sólo parcialmente, por haberse perdido el original- el escrito recriminatorio que el sumo pontífice envió por medio del diácono Turnino a los obispos participantes en dicho concilio.

Con anterioridad a Honorio I, varios concilios de distinto alcance y al menos dos papas: San Gelasio I (aa. 492-496) y San Gregorio Magno (aa. 590-604) habian intervenido en asuntos relativos al bautismo y ordenación sagrada de herejes y circuncidados, manumisión de esclavos convertidos, culto a las imágenes, respecto a las sinagogas, etc. Pero fue Honorio I quien, por primera vez, recrimina públicamente, no a un obispo concreto sino al colectivo de los obispos españoles y de la Galia Narbonense, la tolerancia y blandura observada por éstos en los tocante al comportamiento, convivencia y trato de los cristianos con los judíos.

Ph. Jaffé en la Regesta Pontificum Romanorum recoge, en breve párrafo, el contenido de la carta-decreto de Honorio I a los conciliares participantes en el VI de Toledo.

Ph. Jaffé en la Regesta Pontificum Romanorum recoge, en breve párrafo, el contenido de la carta-decreto de Honorio I a los conciliares participantes en el VI de Toledo.

Dice así: «Honoris I... episcopis totius Hispaniae atque Narbonensis Galliae in Concilio VI (a.638, IX lanuario, celebrato) adunatis per Turninum diaconum decretum mittit, quo et robustiores pro fide et alacriores in perfidorum rescindenda pernicie sint ${ }^{5}$.

El papa exhorta y manda al episcopado español y galo a que, movidos por la fe y celo apostólico, sean fuertes y más valientes en la vigilancia y corrección de la perfidia judía, procurando a la Iglesia de Cristo y a sus miembros los medios necesarios para defenderla de las burlas e injurias que recibe de renegados, impíos y de apóstatas abominables.

Aunque el tenor documental de los cortos retazos conservados de la carta pontificia es muy duro y así lo confirman las frases de contestación y contrarréplica de San Braulio, yo, personalmente, desconozco el alcance de tan fuerte reproche y lo interpreto no en sentido amplio sino más bien restrictivo y como referido no a todos los herejes sino a casos y ofensas de máxima gravedad, rayanas en el ultraje a la Iglesia, a la fe y al cristianismo. No es fácil conciliar la conducta benévola y transigente del papa

5 JaffÉ, Ph., Regesta Pontificum Romanorum, ed. Anast., t. I. Graz-Lipsiae 1956, pág. 226, ก. 2038 
Honorio, rayana en el descuido y negligencia, al enfrentarse con la herejía y doctrina "monoteleta» que le mereció la condenación pontificia (682) y conciliar (a. 692), con la postura intransigente y medidas drásticas propuestas por él a la jerarquía española, máxime si la exhortación y mandato pontificios debían extenderse a todo tipo de herejes, incluidos los judios.

A la recomendación y mandato pontificios de que los obispos sean más firmes en la defensa de la fe y más ardorosos en contradecir a los infieles y en atajar la plaga de los renegados, hace referencia al siguiente párrafo extraído de la carta-respuesta de San Braulio al pontífice de Roma: «Nam iam totius Ispanie adque Narbonensis Gallie episcopi in uno quoadonati eramus collegio quando, Turnino deportante diacono, vestrum nobis est adlatum decretum, quo et robustiores pro fide et alacriores in perfidorum essemus rescindenda pernicie” ${ }^{6}$.

La repuesta de San Braulio -respetuosa y correcta y, a la vez, valiente, audaz y aclaratoria, por entender que la información de que disponía la Santa Sede era inexacta y, en algunos puntos, falsa- permite suponer que tanto al obispo de Zaragoza como al resto de los padres conciliares pareció fuera de lugar y de tono, tanto el tenor del escrito como su contenido y pretensiones, en problemas tan delicados como la política gubernativa, la convivencia, libertad y relaciones entre cristianos y judios. Las recriminaciones del papa fueron tomadas por la asamblea episcopal como gravemente ofensivas para quienes con celo y dignidad gobernaban las distintas parcelas de la Iglesia nacional española y parte de la gala $^{7}$.

Una de las acusaciones que más debió doler a San Braulio y, en general, a todos los padres conciliares, fue, sin duda, la calificación que el papa hacía del episcopado español, aplicándole las palabras de Isaías: "Pastores adormecidos $e$ indiferentes y perros mudos y sin fuerza para ladrar" (Isaías 56,10), incapaces de advertir los peligros que amenazaban a la Iglesia católica y a las almas, tanto de los infieles y desesperados como de los ofuscados y aferrados a prácticas y tradiciones opuestas a la conversión y al conocimiento de Dios.

- Epístola XXI de S. Braulio. Sigo la edición de mi hermano L. Riesco Terrero, Epistolario de San Braulio, Introducción, edición crítica y traducción. Sevilla 1975, págs. 108-115. Esta misma carta puede consultarse en las obras de MADOZ, J., Epistolario de San Braulio de Zaragoza. Madrid 1941; Risco, España Sagrada, t. 30 y LYNCH, C. H. y GaLINDO, P., San Braulio obispo de Zaragoza. Su vida y obras. Madrid 1950.

Copio el texto latino, correspondiente al párrafo vertido al español, con cierta libertad. conforme a la ed. citada de L. Riesco Terrero, Epistolario de San Braulio..., pág. 110: "Quod ne apostolatus vestri apex consideret a nobis extricationis et non veritatis causa depromi, retro acta temporum gesta cum (h)actis presentibus vobis arbitrati sumus necessario esse mittenda». 
El papa Honorio I, contemporáneo de los reyes visigodos: Sisebuto, Suintila, Sisenando y Chintila, mantuvo relación epistolar con alguno de ellos e, indudablemente, debió conocer la postura político-religiosa y disposiciones adoptadas por dichos monarcas respecto de los judíos.

San Braulio (Epístola XXI) entiende que, además de responder con serenidad y valentía, era preciso adjuntar pruebas justificativas de la conducta y actitud tomadas por el episcopado ante la problemática política y religiosa surgida en torno a los judíos. De ahí que con la carta adjunte no sólo las actas del VI Concilio de Toledo (a punto de concluir) sino también las actas de los concilios precedentes, es decir, las correspondientes a los concilios III (a. 589) y IV (a.633), cuyas disposiciones antijudías reproducen, si no la letra, al menos el espíritu de los decretos y leyes insertos en las Leges Visigothorum y "Fuero Juzgo" sobre la erradicación drástica del judaísmo y el sometimiento de los hebreos a la normativa general del reino, con pérdida de sus derechos y libertades y la consiguiente obligación de convertirse por la fuerza al cristianismo o de exiliarse.

He aquí las palabras del obispo cesaraugustano, escritas en nombre de la asamblea conciliar: «Para que vuestra santidad (Honorio I) no piense que, cuanto decimos sobre este asunto (judíos), lo hacemos por disculparnos y no por ser verdad, hemos creído que debíamos enviaros las actas de los Concilios pasados junto con las de éste (que acabamos de celebrar)".

¿Estaba el papa de acuerdo con la política antijudía sancionada por las autoridades civiles y eclesiásticas de la España visigoda? En mi modesta opinión y creo que también en la de San Braulio, así parece. Y esto por dos razones: a) la alabanza que el pontífice hace del rey Chintila y b) la buena acogida que da a sus leyes intolerantes de carácter inquisitorial y coactivo, encaminadas a la consecución de la unidad religiosa y política en todo el reino.

El papa -desorientado por la postura de Sisenando que critica la falsa conversión de los judíos forzada por Recaredo y, sobre todo, por Sisebuto, que reacciona contra la tolerancia religiosa de Suintila al permitir la vuelta al judaísmo de los cristianizados contra su voluntad o por engaño-, se sorprende aún más por la abierta contradicción ideológica y normativa existente, al menos en la práctica, entre los cánones de los Concilios III y IV de Toledo y el VI de la misma serie, relativos a los judíos.

No cabe duda que durante el mandato de Sisebuto y, sobre todo, de Suintila, dentro de la severidad y tirantez, existía cierta benevolencia y tolerancia en la aplicación de las leyes e imposición de las penas a los 
judíos y este mismo talante y trato más humano se observa en San Isidoro de Sevilla, en Aurasio, metropolitano de Toledo, en San Braulio de Zaragoza y en otros obispos y padres hispanovisigodos.

El excesivo celo y vigilancia de Honorio I, defensor y guardián a ultranza no sólo de la fe cristiana sino también de los derechos de los cristianos y de la casa de Dios, la Santa Madre Iglesia, pudo inducirle erróneamente a elogiar y amparar la política antisemítica del rey Chintila, política tolerada a la fuerza por la mayoría de los obispos, pero no compartida ni llevada a sus últimas consecuencias por ellos en materia penitencial y disciplinar, a pesar del rigor y dureza de los cánones 57-67 del VI Concilio de Toledo.

El movimiento de rejudaización y permiso de retorno al judaísmo, bien por asimilación, bien por convencimiento o por razones de tipo social, económico o político, en tiempos de Suintila (aa. 621-631), y la no exigencia de lo preceptuado por Sisebuto, debió preocupar seriamente al papa Honorio, responsable y custodio supremo de la fe y santidad de la Iglesia. Esta preocupación aflora en su escrito, dirigido a los padres conciliares reunidos en Toledo a principio del año 638, a quienes con palabras duras trata de corregir $y$, también, de alentar, para que siguiendo el ejemplo y propósitos del rey atajen con prontitud y energía el proselitismo, sean más ardorosos y firmes en la defensa de la fe, cumplan fielmente con los deberes que implican sus cargos de pastores y guias espirituales y no se dejen doblegar por la tibieza, la benevolencia o las dádivas, a la hora de aplicar la normativa civil y canónica relativa a los judíos, apóstatas, herejes y paganos.

Atribuir al papa Honorio la propuesta a los obispos de aplicar penas mayores a la consignadas en las leyes, decretos y plácitos de los monarcas visigodos, radicalmente opuestos a las comunidades y guetos judíos, incluyendo en ellas el destierro, la confiscación de bienes, la incapacitación para todo tipo de cargos públicos y, sobre todo, la pena capital, me parece ir demasiado lejos $y$, por supuesto, infundado, si se tiene en cuenta la documentación de que disponemos, la benevolencia natural del papa y la postura, en estos puntos, de dos de las figuras más sobresalientes de la España e Iglesia visigodas: San Isidoro y San Braulio.

\section{CONTESTACIÓN DEL OBISPO DE ZARAGOZA, SAN BRAULIO, AL PAPA HONORIO 1}

La forma de expresarse el obispo cesaraugustano en su carta de contestación al escrito del pastor supremo de la Iglesia de Roma indica que, 
San Braulio - a modo de portavoz y en representación de todos los obispos de España y de los pertenecientes a la Galia Narbonense- redactó dicha carta como respuesta obligada pero, a la vez, como explicación y justificación de su postura ante problemas pastorales y políticos de gran importancia. No sabemos la fecha exacta de esta carta. Seguramente debió escribirse en los primeros meses del año 638 al finalizar el VI Concilio de Toledo.

La preeminencia indudable de San Braulio entre el clero y pueblo visigodo, sublimada en extremo y sacada de los límites razonables, ha servido de argumento base a algunos historiadores para convertir al obispo de Zaragoza en inspirador y responsable no sólo de las decisiones gubernamentales (Chintila) y conciliares sino también de la política antijudía sancionada en el Concilio Toledano VI.

Creo, con toda sinceridad, que no existen argumentos serios para echar sobre sus espaldas semejante acusación, al menos en lo referente a la incomprensión y política antijudía.

En su largo escrito, San Braulio reconoce y alaba el celo apostólico con que el pastor espiritual supremo cuida, tanto de la Iglesia católica como de las distintas iglesias nacionales y locales, de sus obispos, clero y fieles. El escrito pontificio dirigido a los padres conciliares de Toledo es la mejor prueba de su interés y celo por la santificación de la Santa Madre Iglesia y por la conservación y propagación de la fe cristiana.

Esta deferencia del papa y las facilidades dadas a los obispos por el rey Chintila deben considerarse como una gracia especial, procedente -a juicio de San Braulio- de la inspiración divina, y digna de agradecimiento por parte de todos los prelados españoles.

Las censuras y recriminaciones vertidas por el pontífice contra el episcopado visigodo debieron ser $o$, al menos, así les parecieron a los obispos, demasiado fuertes.

Los calificativos a que alude San Braulio dejan a la jerarquía hispanovisigosa en mal lugar y rayan en el desprestigio. He aquí algunos: "excesivamente indulgentes y tolerantes con los judíos, apóstatas y renegados", "tibios en la fe e indolentes en cuanto al cumplimiento de sus deberes pastorales", "poco evangélicos y ardorosos en la predicación y extensión del reino de Cristo en la tierra: la Iglesia", y, sobre todo «apocados, negligentes y despreocupados" en lo tocante a la protección de las iglesias diocesanas y al cuidado espiritual de los fieles encomendados.

En ningún momento habla el papa - al menos por lo que se desprende de la carta de San Braulio- del empleo del engaño, la amenaza o la 
fuerza ni tampoco de la muerte, destierro, castigo temporal o pecuniario, etc., como medios adecuados para someter y doblegar la incredulidad de los enemigos de la cruz de Cristo y de cuantos, por error, debilidad, egoísmo, etc., se oponen a abrazar la fe católica o abandonan el seno de la Iglesia para volver, mediante la «rejudaización», a su viejo error.

Resumo las razones, respetuosamente expuestas por San Braulio, exponente de la energía y santa libertad de un obispo español que piensa (siglo xII) que la Iglesia y el papa no pueden proceder, ni legislar como el rey o su corte.

1. La actuación y acusaciones del papa llamando la atención a los obispos visigodos, aunque legítimas y dignas de agradecimiento, por caer dentro de su oficio y competencia, son excesivamente duras $y$, en cierta medida, injustas y falsas por no corresponder a la realidad. El papa, en lugar de corregir como padre y con la humildad de la verdad, amenaza y castiga como juez implacable.

2. Dichas acusaciones, sólo pueden proceder -en palabras de San Braulio- de la mentira, de chismes absurdos y rumores anónimos, de la deficiente y maliciosa información llegada a Roma o de la excesiva credulidad de que, sin duda, ha sido víctima el cabeza supremo de la Iglesia.

3. El hecho de que los obispos de España y de la provincia eclesiástica de Narbona se hayan reunido en sucesivos concilios y en este VI Toledano, a punto de concluir, para tomar medidas disciplinares adecuadas sobre distintos asuntos de interés general, entre los cuales figura el problema de los judíos, la corrección de los abusos y malas costumbres introducidas, etc., es la mejor prueba del celo, interés y cuidado de los pastores y guías de las iglesias locales por el bienestar y limpieza de la Iglesia y de sus hijos, los fieles cristianos.

4. Para hacer más patente la solicitud espiritual y vigilancia del episcopado español y la sinrazón de la acusación pontificia, que los equipara y llama: «Perros mudos, incapaces de ladrar» y "pastores adormecidos", en cuanto al celo apostólico y represión de los judios, apóstatas y renegados, «hemos creído - dice literalmente el texto de la carta XXI de San Braulio- que debíamos enviaros las actas de los concilios pasados junto con las de este VI de Toledo, en cuyos cánones aparece ampliamente tratada dicha temática y la postura colegial adoptada por los padres conciliares".

5. A los obispos españoles les ha llegado el rumor de que el propio príncipe de la Iglesia y obispo de Roma había autorizado, por 
decreto (rescripto) pontificio, que los judíos bautizados, abandonando la fe cristiana y apartándose de la Iglesia católica, pudieran volver a la práctica de su religión. Sin embargo, ninguno de ellos (obispos) admitió tal rumor ni dio el menor crédito a semejante noticia. El papa, en cambio, sin indagar la verdad, ha creido ingenuamente los relatos, en unos casos, infundados y, en otros, falsos, de personas de ninguna credibilidad, los cuales con toda probabilidad le indujeron a escribir tan dura y recriminatoria epístola.

6. Finalmente, San Braulio insiste en que los obispos han hecho público, en lugares adecuados, los castigos de los transgresores y han cumplido con el deber de predicar y evangelizar, pero que aun tratándose de renegados, judíos, pecadores públicos e incrédulos habian preferido actuar con caridad, dulzura y habilidad conforme al mandato de Cristo, costumbre de la Iglesia y recomendación de los Santos Padres antes que con amenazas, rígidos castigos o por la fuerza. Convendría -añade el obispo de Zaragoza al final de su carta - que el papa, cabeza y responsable de la Iglesia, ponderara y meditase seriamente si los implicados en cualquier tipo de culpabilidad deben ser castigados con penas tan severas como las enunciadas por el pontífice como remedios eficaces y saludables para los arrianos, apóstatas y renegados. Los padres conciliares no recuerdan que tales penas se hayan aplicado en parte alguna por sus predecesores ni que tales castigos figuren, como palabra de Cristo, en las páginas del Nuevo Testamento.

Este último punto de la carta enviada a Roma, indica que tanto San Braulio como el resto de los obispos visigodos estaban dispuestos a seguir en este asunto la práctica y consejo de sus antecesores en las sedes de España, de los insignes doctores y padres españoles y de la propia Iglesia, es decir, practicando más el sentido común, la caridad, el celo y la prudencia que la amenaza, la fuerza y el castigo, aún en el caso de quienes por ignorancia, error, malicia o convicción se oponían a abrazar la fe cristiana.

\section{EL REY CHINTILA}

Para muchos autores, el rey Chintila fue el primero de la monarquía católica visigoda en dar pasos decisivos para erradicar el judaísmo de sus reinos, aplicando la política de la conversión por la fuerza o el destierro a quienes se resistiesen a su proyecto. 
Sin ningún miramiento y deseoso exclusivamente de conseguir y afianzar - por las buenas o por las malas - la unidad política y religiosa en todo el territorio, el rey actúa como autoridad soberana y fuente única de todas las leyes sin ningún tipo de limitación; junto a la seguridad y bien general del reino y de sus súbditos, estaba la de su persona y familia y, en definitiva, la de la corona. Con estos fines, el rey convocó dos concilios, el $\mathrm{V}$ y $\mathrm{VI}$ de Toledo que, a su vez, fueron cortes generales del reino visigodo.

Los dos brazos principales y más representativos de la nación: el eclesiástico y el secular (nobleza), unidos a la cabeza visible y suprema del pueblo: el rey, debaten y legislan sobre asuntos eclesiásticos y civiles, encargándose el propio monarca de aprobar y dar fuerza legal a las decisiones tomadas (normalmente con su beneplácito) mediante la promulgación oficial de las mismas.

En el Concilio $V$ toledano (a. 636), Chintila se reserva el poder de indultar y perdonar los delitos y culpas de delincuentes, infieles y desertores iuxta bonitatis et pietatis sue, siempre que exista en ellos el arrepentimiento.

El término "delincuentes" hace referencia directa a los conspiradores y enemigos del monarca, de la familia real, del reino y de la corona e, indirectamente, a quienes por razón de ideología, religión o motivaciones de índole política, social, económica..., impedían la paz y concordia de los súbditos 0 no eran merecedores de la confianza regia (cánones 8 y 9).

Basado en disposiciones precedentes, de origen real y conciliar, sobre unificación del culto público y modo de celebrarlo o de administrar los sacramentos v.gr. Pascua de Resurrección, Cuaresma, Semana Santa, bautismo, matrimonio, etc., y, sobre todo, en los preceptos antijudios de Recaredo, Sisebuto y Sisenando, sin atender para nada a la aplicación benévola, por parte de los obispos, de dicha normativa, Chintila endurece las medidas coactivas de represión no contentándose con la observancia aparente y respeto de los reincorporados al judaísmo tras el abandono de la religión cristiana. El rey, convertido en árbitro supremo de vidas y conciencias, obliga, contra toda norma eclesiástica, a los judíos: conversos o no conversos, a abjurar de su religión y errores y a bautizarse por la fuerza como símbolo de su conversión.

En lo sucesivo, la violación del juramento -exigido por la ley para garantizar la estabilidad y conservación de la patria, la vida del rey y del pueblo godo y la integridad de la fe cristiana (c. $75, \Phi 2$ y 3 )-implicaría el extrañamiento y separación tanto del reino como de la Iglesia católica, 
con las consiguientes sanciones, penas y privaciones explicitadas en el canon 3 del VI Concilio toledano y en la Placitum regio, que se obligó a firmar a los judíos de Toledo ${ }^{8}$.

Ante esta postura intolerante y discriminatoria para con los judíos, adoptada por Chintila y, en cierto modo, aprobada o, al menos, tolerada por San Braulio y el conjunto de obispos visigodos en España y de parte de las Galias, cabe pensar en el apoyo moral ofrecido al rey por parte del papa Honorio I, al menos en lo tocante a la normativa antijudía respecto de renegados y recaídos en las viejas prácticas mosáicas. Pero la intolerancia y discriminación real pudieron proceder de circunstancias y problemas coyunturales de diversa índole, v.gr. atentados, sublevaciones, rebeliones, etc., surgidos a última hora, de la mentalidad del propio rey en cuanto a la unidad político-religiosa de gobierno que suponía idénticas leyes e idéntica profesión confesional para todos los súbditos y moradores del reino y del talante temperamental de este monarca a la hora de aplicar las leyes civiles y eclesiásticas.

Está por saberse si el papa Honorio, al escribir su carta a los padres conciliares de España, lo que intentaba era que el episcopado apoyase decididamente a Chintila y no le pusiese obstáculos en orden a conseguir la paz y mantener el reino o, más bien, que no tolerasen a herejes, judíos, apóstatas, etc., violar la fe católica a causa del soborno y de la indiferencia.

San Isidoro, con toda su autoridad y prestigio, ni siquiera con el apoyo de los padres sinodales que intervinieron en los Concilios III de Sevilla y IV de Toledo logra imponer sus criterios en materia de fe. Forzado - como sus compañeros- por el poder autoritario e ilimitado de los monarcas, tampoco pudo impedir las actuaciones y leyes antijudías vinculantes para súbditos y autoridades de todo tipo. Su condición de hombre sabio, santo y de gran experiencia en temas tan delicados como el de la libertad religiosa, inherente a la condición humana, aun tratándose de delito, herejía, error, infidelidad, animadversión... contra la Iglesia católica, procedente de herejes, judios, apóstatas, exiliados... le inclinan más a la moderación y prudencia, a la aplicación del precepto evangélico de la caridad y al uso de la razón e instrucción que a la imposición de la verdad por la fuerza bruta o por el fanatismo, aunque la norma sancionadora gozase del respaldo de la autoridad real.

- Los "Placita” de Chintila y Recesvinto puede verse en FITA, F., "El Papa Honorio I y San Braulio de Zaragoza". "La Ciudad de Dios, $n .^{\circ} 4,1870$, págs. 189-201 y 264-278; $n .{ }^{\circ} 5,1871$, págs. $275-289,358-263$ y $447-458 ; n .{ }^{\circ} 6,1871$, págs. $421-429$ y en las "Leges Visigothorum», $\mathrm{XII}, 2,17$. 
La recia personalidad de su mejor amigo y discípulo predilecto, San Braulio, puesta de manifiesto en la vida política y eclesiástica de España $y$, de modo especial, en sus intervenciones en los Concilios IV, V y VI de Toledo, tampoco permitieron al obispo de Zaragoza adoptar una postura de abierta oposición a las medidas y leyes discriminatorias contra los judíos y a la política de conversión forzosa, tanto de Sibebuto como de Chintila ${ }^{9}$.

En cambio, su actuación con relación al papa Honorio I, aparte de valiente y decisiva, fue distinta. San Braulio desmiente, por falsas e infundadas, las acusaciones y responsabilidades que se les imputan y, sobre todo, rechaza el rigor y severidad de las penas y castigos que el pontífice - siguiendo las trayectorias y política regia - intenta aplicar a judíos, apóstatas y herejes por considerarlas -como dije más arriba-contrarias a la doctrina evangélica de la caridad, a la enseñanza de los doctores y santos de la Iglesia española y ajenas a la tradición general de la Iglesia.

Enjuiciar con rigidez y criterios actuales la actuación de determinadas personas, cuya mentalidad, vida y actividades corresponden a épocas y circunstancias históricas de tiempos pasados ${ }^{10}$, implica, con frecuencia, la descalificación del enjuiciado y la exigencia en todo momento de una conducta si no heroica al menos intachable aun a costa de la propia vida $y$, por supuesto, de bienes y cargos. Este riesgo y otras consecuencias

9 La contestación que S. Braulio da a distintas consultas formuladas por el presbítero y abad Frunimiano, sobre la postura y conducta a observar en momentos de contrariedad, persecución o duda, es tajante: "No existe empresa sin peligro y quienes quieran vivir piadosamente en Cristo - como dice el Apóstol- sufrirán persecución. Pero, en todo caso -añade ęl obispo de Zaragoza - hay que perseverar en la misión encomendada y en la obra emprendida, siendo justos y, a la vez, clementes, odiando el pecado y no a los hombres pecadores, usando la tolerancia con los débiles y la energía con los soberbios..., pero ofreciéndoles en todo momento la dulzura dela caridad y dejando el futuro, siempre incierto, en manos de Dios" (Epist. XIII). Y con relación a las normas sobre unificación de ritos y modo de celebrar los oficios litúrgicos, aprobadas en el IV Conc. de Toledo y ratificadas por el rey y por el propio S. Braulio, escribe a ruegos del mencionado abad Frunimiano: «A tu juicio corresponde elegir, de las disposiciones conciliares y de cuanto te digo, lo que mejor te parezca y si no te gustan, puedes corregirlas o suprimirlas" (Epist. XIV). RIESCO TERRERO, L., “Epistolario...”, op. cit., págs. 89-91 y 93.

10 Grande debía ser la preocupación y temores de S. Braulio por la inseguridad e incertidumbre política y social del reino en tiempos de Chindasvinto cuando él, con el apoyo del obispo de Valencia, Autropio, del clero y del pueblo fiel a ellos encomendado, se atreve a solicitar de su señor y rey que, mientras viva, asocie al gobierno de la corona a Recesvinto para que éste, aún joven y con fuerzas, pueda guerrear y soportar el esfuerzo y riesgo de las campañas bélicas y acaben de una vez las asechanzas y amenazas de los enemigos y la vida del pueblo honrado y leal discurra tranquila. Epistolario de San Braulio, ed. L. Riesco Terrero, CartaSúplica, n. 137, págs. 148-149. 
de signo negativo para los oponentes y aun para la paz y desarrollo de la vida de la Iglesia los corrieron los mártires y santos en tiempos de las persecuciones $y$, también, los obispos visigodos $y$, en general, todos aquellos que se resistieron a las decisiones injustas de quienes con poderes omnímodos y por la fuerza, en lugar de buscar el bien común bajo el amparo de la ley justa, impusieron la arbitrariedad y su propio capricho ${ }^{11}$.

Si la dureza de Chintila, contra judíos y cristianos judaizantes y, en general, contra el proselitismo religioso de los hebreos y conversos, no llegó al límite de la intolerancia y de la discriminación, al menos abrió el camino para que, un sucesor suyo, F. Recesvinto, reavivase contra ellos, desde el punto de vista legal, el más acerado rechazo y violenta persecución inquisitorial, como lo muestran su nuevo placitum, de mediados del siglo VII, contra los judíos toledanos y, sobre todo, el Título III, Libro XII de las "Leyes Nuevas de los Judíos", codificadas en el Fuero Juzgo o Liber ludiciorum.

\section{CONCLUSIONES}

A modo de conclusiones, resumo en unos cuantos puntos lo más sobresaliente de mi exposición:

1. A mi juicio el rechazo e incomprensión histórica del judaísmo, en unos casos, y el aplauso y simpatía, en otros, es un fenómeno complejo tan antiguo y tan nuevo como el propio pueblo hebreo, que no se debe exclusivamente a su religión e ideología, sino a múltiples causas y concausas, ni en modo alguno se ciñe y concreta a España y a los españoles de los siete primeros siglos de nuestra era.

2. La tradicional animadversión y lucha entre cristianos y judíos del período aquí estudiado, obedece más a circunstancias y asuntos

11 Datos interesantes sobre la rudeza y modo sorprendente e injusto de actuar del pueblo godo y, sobre todo, de sus monarcas tras la conversión al catolicismo (año 589 ) pueden verse en Thompson, E. A., “Los godos en España», págs. 179-248. Yo por mi parte, resalto algunos que considero significativos. Chintila, a quien cito a modo de ejemplo, no sólo fuerza, mediante Leyes y plácitos, las conversiones de los judíos. En más de una ocasión obligó a los metropolitanos de Toledo a ordenar de sacerdote, contra su voluntad, a candidatos indignos; violó la normativa sobre el procedimiento de elección real establecida en el IV Concilio de Toledo y, desoyendo los ruegos de $S$. Braulio, privó a este anciano obispo de su mejor colaborador: el arcediano Eugenio, para convertirlo en metropolitano de Toledo (Epist. XXXI, XXXII y XXXIII; Riesco Teraero, L., Epistolario de San Braulio, págs. 128-135). 
político-disciplinares $y$, sobre todo, al talante protector $u$ hostil de los emperadores romanos y reyes visigodos que a dogmas y puntos doctrinales propugnados por la Iglesia católica en sínodos y concilios.

3. ${ }^{\circ}$ A la carta recriminatoria de Honorio I, dirigida a los padres conciliares, reunidos en Toledo el año 638, por su tolerancia, blandura y pasividad ante el peligro que suponía para la Iglesia el proselitismo, osadía y comportamiento de los judíos, debe darse un alcance restrictivo y sólo para casos notorios de probada gravedad y malicia. Su postura antijudía obedece más a rumores anónimos y bulos infundados, a presiones políticas, a informes maliciosos y parciales llegados a Roma y a la excesiva credulidad y ligereza del pontífice que a la situación real y peligros a que alude y trata de corregir y subsanar.

4. ${ }^{\circ}$ La jerarquía católica de la Iglesia visigoda, principalmente la española, con todos sus defectos y debilidades, fue la única fuerza de oposición 0 , cuando menos, de mitigación práctica a las medidas de fuerza y disposiciones antijudías dadas por determinados monarcas: Recaredo, Sisebuto, Suintila, Sisenando y Chintila.

5. Las figuras más señeras e influyentes del episcopado visigodo: San Isidoro y San Braulio, en el tema de la conversión forzosa de los judios, abogaron mucho más por la aplicación de la tolerancia, instrucción y corrección evangélica que por la imposición violenta y el castigo, que sólo admiten en casos excepcionales y de extremada gravedad.

6. Circunstancias de orden político y seguridad del Estado y, sobre todo, la cerrazón, dureza y poderes omnímodos de varios reyes visigodos, obligaron a la jerarquía eclesiástica española a tolerar y aun a aprobar en Toledo normas conciliares que, poco o nada, dicen en pro de la Iglesia católica y mucho en favor de los judíos. El enfrentamiento y lucha abierta contra decisiones regias - a nuestro modo de ver- injustas e ilegales, hubiera exigido de todos y cada uno de los obispos visigodos temple heroico y vocación de mártires en multitud de ocasiones, cualidades nada fáciles $y$, menos, exigibles. En último término, ignoramos si esta actitud y resistencia, tan deseada por algunos, fueron o no posibles $y$, sobre todo, si de haberlas tomado habrian sido más eficaces y provechosas para la Iglesia y para el cristianismo. 
Recensiones 